\title{
The effectiveness of the use of a powered roof support in the light of research and analysis
}

\author{
Dawid Szurgacz ${ }^{1, *}$ \\ ${ }^{1}$ Center of Hydraulics DOH Ltd, ul. Konstytucji 147, 41-906 Bytom, Poland
}

\begin{abstract}
A powered roof support is an element of a longwall complex. It is connected with a scraper conveyor by a sliding system. The conveyor carries a shearer mining the coal. The second function of the powered roof support is to protect the excavation against uncontrolled impact of the rock mass. This paper focuses on the analysis of the effectiveness of the powered roof support. The main objective is to determine the factors influencing failure-free operation in the exploitation process. Moreover, the author discusses performance requirements for the powered roof support.
\end{abstract}

\section{Introduction}

The operational reliability of machines in the coal mining process is one of the factors determining their level of use. The second factor that we have no influence on is the natural hazards associated with coal mining. The most unpredictable, having a significant impact on the maintenance of continuity of operation of a powered roof support, is mining tremor hazard. The greatest influence on the operation of the entire complex has a methane hazard, therefore the ventilation system must be properly designed to reduce hazardous methane concentrations $[1,2]$. The choice of an adequate ventilation method is fundamental. The efficiency of the powered roof support is also affected by preoperational factors, such as: preparation of the structure based on the analysis of mining and geological conditions and assessment of usefulness and suitability.

The operation of the powered roof support in the production (mining) system includes the following stages: putting it into service, operating in the mining system and excluding it from the mining system. Effectiveness is one of the basic categories used to describe the state, functioning and development opportunities of various types of enterprises. The concept of effectiveness is most often understood as the mutual relations between the inputs and refers to the principle of rational management. A different approach to the issues related to the powered roof support can be found in the literature [3-6]. Underground hard coal mining companies often apply the concept of technical efficiency, understood as maximising the production volume with the use of the given input [7-8].

Therefore, it can be assumed that the correct effectiveness of a single unit of the powered roof support and of the whole section constituting the technical system protecting a longwall excavation depends on their use and constitutes one of the basic tasks performed during their exploitation.

${ }^{*}$ Corresponding author: dawidszurgacz@,doh.com.pl 
The main tasks formulated in the field of system operation include the following technical tasks:

- extending the effective working time of the exploited longwall complex,

- shortening the time of renovation of the service life of the powered roof support with simultaneous improvement in the quality of renovation,

- increasing the durability and reliability of support sections,

- reducing the wear of parts,

- optimising spare parts management,

- improving conditions in the use of the roof support,

- improving occupational safety of employees,

- protecting the roof support against natural hazards.

In order to perform these tasks, it is necessary to properly organize and control the production process. One important factor in influencing specific actions in this area is the adoption of an appropriate methodology for monitoring and evaluating the effectiveness of the use of machinery and equipment used.

\section{Powered roof support effectiveness}

The assessment of the degree of utilization of the powered roof support in a hard coal mine is based on various measures. So far, the solutions used in the area of management of means of production have been focused on independent use of the area in information. All information from the production process is a basic database of information on the need to make decisions of any kind. The basic feature of assessing the effectiveness of the powered roof support section is its reliability and ease of maintenance.

Two ratios are used to assess these two characteristics. Reliability is most often measured by Mean Time Between Failures (MTBF). It is the average time between failures or the frequency of failures, and the ease of maintenance by means of Mean Time to Repair (MTTR) [9-12]

The methods of calculating these indicators are as follows:

- MTBF, mean time between failures or frequency of failures, is understood as the average time between failures over a specified time. This indicator is calculated by the following formula:

$$
M T B F=\frac{\text { working time }}{\text { number of failures during given time }}
$$

- MTTR, mean repair time, is understood as the average duration of the actual repair from the moment of notification until its completion. It is calculated by the following formula:

$$
M T B F=\frac{\text { repair time }}{\text { number of failures }}
$$

Another indicator that plays an important role in improving the production process is Overall Equipment Effectiveness (OEE).

- OEE, total equipment effectiveness.

The indicator is based on three other parameters as in the following formula:

$$
O E E=\text { availability } x \text { performance } x \text { quality } x 100 \%
$$

Availability is calculated by the formula: 


$$
A=\frac{\text { run time-stop time }}{\text { run time }}
$$

where:

$$
\text { stop time }=\text { maintenance }+ \text { changeover }+ \text { failures }+ \text { other }
$$

Performance is calculated as:

$$
P=\frac{\text { Total count (Good }+ \text { bad quality) }}{\text { Run time } x \text { Ideal Cycle Time }}
$$

Quality is calculated as:

$$
Q=\frac{\text { Total count }- \text { shortages }}{\text { Total count }}
$$

A time base is determined, which is a key factor, in order to calculate the value of OEE. A commonly accepted interpretation of a methodological standard is that the base time is the total planned production time. It is understood as organisational time-simultaneous availability of the human and machine factor for production. All aspects related to the observation of the individual layers present in the OEE methodology (availability, performance, quality), under the conditions of deep mining, are possible with respect to either the mining machine, or the longwall complex, or even more broadly to the whole technological sequence - from the longwall face mining to transporting the output to the surface. The final idea of the presented indicator is to develop a tool for systematic control of the effectiveness of the production process, aimed at reducing the number of failures and faults, and reducing the number of stoppages-

There are many ways in which we are able to get information on whether individual machines work well, but the most important is to determine what is measured. It is therefore necessary to rely on appropriate measures, which are used to evaluate the activities carried out, in connection with specific organizational objectives. There are various criteria that can be applied to assess the effectiveness of the roof support section. Available publications [912] present a number of evaluation criteria (Table 1). For each of the criteria, different types of indicators are used.

Table 1. Examples of types of indicators for assessing the effectiveness of machines.

\begin{tabular}{|l|l|}
\hline Type of criterion & Examples of indicator types \\
\hline \multirow{2}{*}{ Economic } & $\begin{array}{l}\text { - profitability index } \\
\text { - fixed and variable costs of machine maintenance, } \\
\text { - cost ratio of the overhaul, average and current machine } \\
\text { maintenance, } \\
\text { - spare parts maintenance costs. }\end{array}$ \\
\hline \multirow{2}{*}{$\begin{array}{l}\text { Technical and } \\
\text { maintenance }\end{array}$} & $\begin{array}{l}\text { - machine reliability index, } \\
\text { - machine downtime index, } \\
\text { - machine damage and failure index, } \\
\text { - technical readiness index, } \\
\text { - machine utilisation index, } \\
\text { - replacement index. }\end{array}$ \\
\hline
\end{tabular}




\begin{tabular}{|c|c|}
\hline $\begin{array}{l}\text { Information and } \\
\text { operational }\end{array}$ & $\begin{array}{l}\text { - technical development index, } \\
\text { - machine average age index, } \\
\text { - repair intensity index, } \\
\text { - repair satisfaction index, } \\
\text { - maintenance service employment index, } \\
\text { - overhaul, average and current repairs prompt completion } \\
\text { index, } \\
\text { - maintenance ease index, }\end{array}$ \\
\hline Concerning safety & $\begin{array}{l}\text { - number of accidents during operation and use of } \\
\text { machines, } \\
\text { - number of hazards arising during operation and use of } \\
\text { machines. }\end{array}$ \\
\hline
\end{tabular}

\section{Factors influencing the failure-free operation of a powered roof support}

It is a key aspect to properly maintain the machines which are included in the longwall complex in an underground mine. The relations between the machines of the longwall complex (shearer, conveyor, powered roof support) determine the efficiency of extraction. The stoppage of each machine affects the whole mining process. The process of exploitation of the powered roof support consists in a number of phases. As can be seen in Figure 1, the process of exploitation is a set of the following components [9-12]:

- preparing the machine for use,

- ensuring suitability,

- utility processes,

- decommissioning a machine,

- mining management systems.

Exploitation processes also include aging of the machine, understood as a set of all destructive processes, resulting from the influence of forced external working factors, operators' mistakes, etc., on the condition and efficiency of the machines. Defective work of the powered roof support causes a decrease in the quality of production, makes it difficult to maintain its rhythm, disorganizes the work and causes internal and external threats. Defective symptoms do not always occur in the entire longwall complex. First of all, this applies to some parts of the power hydraulics. Therefore, during the construction and manufacture of the machine, basic operational requirements must be determined (Fig. 2.) [9-12]. 


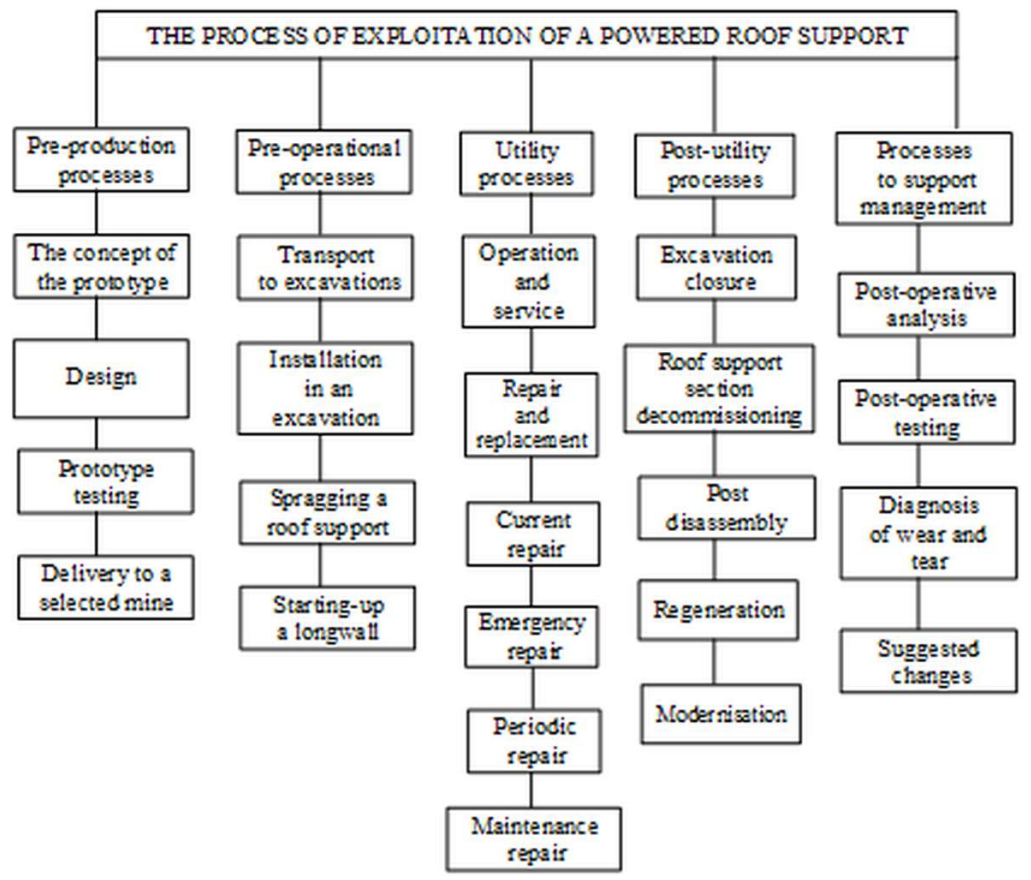

Fig. 1. The operational process of a powered roof support.

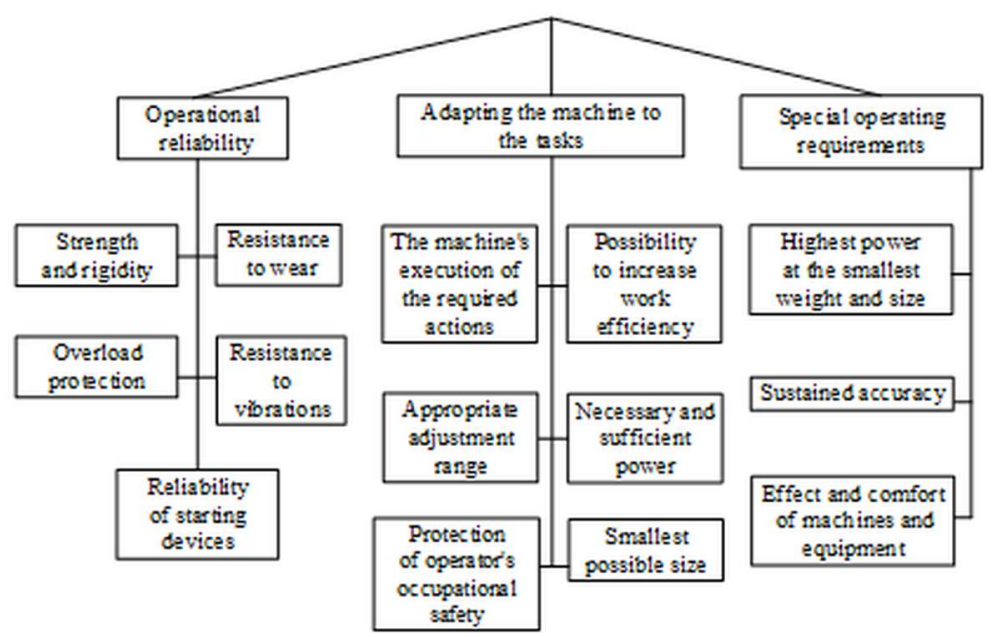

Fig. 2. Operational requirements for a powered roof support.

\section{Assessment of utilization degree of a powered roof support}

Improving the production process in a deep mine is a process of machine management and continuous prevention of natural hazards. The process of management of the machinery of the longwall complex is based on appropriate monitoring. Continuous measurement contributes to increased efficiency and productivity and helps to improve the volume of coal extraction. The improvement process should be based on the use of appropriate tools and methods which will increase the efficiency and effectiveness of the entire mining system. 
The basis of any functioning system are people. Man manages systems, machines, analyses their failures, performs periodic inspections, etc. In order to maintain a high level of machine efficiency in the mining industry the employee must be constantly trained in machine operation and the implementation of new technologies. It should also be remembered that there are many natural hazards in the mine over which we have no control, so every employee is trained to recognise and combat natural hazards.

The assessment of the effectiveness of the powered roof support was based on OEE model, which is widely used in the global economy to measure the effectiveness of machines. The measure of effectiveness for this model is an index - a resultant of three components(subordinate) dimensionless quantities based on three layers relevant for the operation of machines. These are [9-12]:

- Availability, defined as the ratio of the actual working time of the machine to the theoretical machine availability time. Availability is reduced by downtimes (planned or unplanned) which prevent the machines from operating. Actual availability is reduced by failures and, depending on the method used, by machine set-up and changeover. The operating time includes periods of planned downtime.

- Performance is the ratio of the available time minus the machine capacity loss to the actual working time. The performance (use of the machine) is often reduced by the losses resulting from the speed of individual operations.

- Quality, defines the ratio of acceptable production (good quality products) to total production.

The OEE indicator reflects the degree of utilisation of the base time necessary to achieve full production.

Table 2. [9-12] presents a scheme for determining OEE together with the assumptions used in the calculations. It is very important to identify the causes of time losses when determining the value of this indicator for a powered roof support.

Table 2. Diagram of determining OEE.

\begin{tabular}{|l|l|l|}
\hline \multicolumn{2}{|l|}{ Total availability } & Planned downtime \\
\hline A. Actual availability (operating time) & failures, downtimes & \\
\hline B. Actual availability & OEE $=\frac{B}{A} \cdot \frac{D}{C} \cdot \frac{F}{E}$ \\
\cline { 1 - 1 } C. Ideal performance (declared) & availability $\cdot$ performance $\cdot$ quality) \\
\cline { 1 - 1 } $\begin{array}{l}\text { D. Actual } \\
\text { performance }\end{array}$ & $\begin{array}{l}\text { Performance } \\
\text { losses }\end{array}$ & \\
\cline { 1 - 1 } E. Total count & shortages & \\
\cline { 1 - 2 } F. Good count & & \\
\hline
\end{tabular}

Table 3. Value of component factors and OEE for a powered roof support.

\begin{tabular}{|c|c|c|}
\hline Indicator value & Mining tremor hazard & No mining tremor hazard \\
\hline Availability & $80 \%$ & $90 \%$ \\
\hline Performance & $85 \%$ & $95 \%$ \\
\hline
\end{tabular}




\begin{tabular}{|c|c|c|}
\hline Quality & $90 \%$ & $97 \%$ \\
\hline OEE indicator & $70 \%$ & $89 \%$ \\
\hline
\end{tabular}

\section{Conclusion}

The analysis was limited to the powered roof support, excluding the remaining machines of the complex (conveyor and shearer). When calculating the value of OEE, in accordance with the scheme presented in Table 2., operating conditions were assumed, in which extraction is carried out in conditions of mining tremor hazards, where the geological structure of the mining medium is not prone to tremors caused by rock mass. On the basis of the analysis, the OEE index for a powered roof support in the conditions of mining tremor hazards should be within the range of $55-65 \%$, and in the conditions of no mining tremor hazards the index is estimated at $75-85 \%$. The value of the indicator below this range indicates low effectiveness of the use of the roof support, and therefore it is necessary to introduce changes in order to improve this value. Table 3 shows that the average OEE value for the powered roof support at the level of acceptable use should fall within 55 and $70 \%$. The OEE will help the mines to determine the causes and problems occurring in the process of exploitation of devices, machines and systems. The analysis of the value of the indicator should provide a source of information on the basis of which improvements and corrective actions to increase the effectiveness of the production process will be made.

\section{References}

1. M. Tutak, J. Brodny, D. Szurgacz, L. Sobik, S. Zhironkin, Energies ,13(18), 4891 (2020)

2. D. Szurgacz, M. Tutak, J. Brodny, L. Sobik, O. Zhironkina, Energies, 13(17), 4538 (2020)

3. D. Szurgacz, S. Zhironkin, M. Cehlár, S. Vöth, S. Spearing, M. Liqiang, Energies, 14, 697 (2020)

4. J. Wodecki, M. Góralczyk, P. Krot, B. Ziętek, J. Szrek, M. Worsa-Kozak, R. Zimroz, P. Śliwiński, A. Czajkowski, Energies, 13, 6748 (2020)

5. M. Bajda, M. Hardygóra, Energies, 14, 1512 (2020)

6. B. Ziętek, A. Banasiewicz, R. Zimroz, J. Szrek, S. Gola, Energies, 13, 6331 (2020)

7. P. Bortnowski, L. Gładysiewicz, R. Król, M. Ozdoba, Energies, 14, 1786 (2020)

8. P.J. Borkowski, Energies, 13, 6274 (2020)

9. K.E. McKone, R.G. Schroeder, K.O. Cua, Journal of Operations Management, 18, 123144 (1999)

10. P. Muchiria, L. Pintelona, L. Geldersa, H. Matrinb, International Journal of Production Economics ,131(1), 295-302 (2011)

11. R. Oechsner, M. Pfeffer, L. Pfitzner, H.Binder, E. Muller, T. Vonderstrass, Materials Science in Semiconductor Processing, 5, 333-339 (2002)

12. S. Rathenshwar, D.S. Dhaval, M. Ashish, H.S. Milesh, Automation through Hardware \& Software Development Procedia Engineering, 5, 579-584 (2013) 